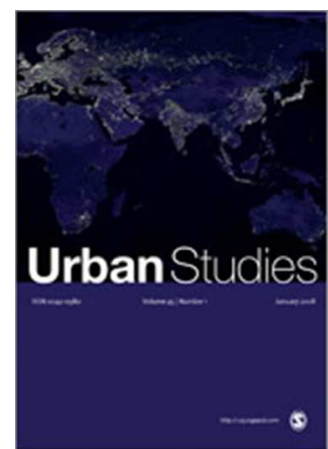

\title{
Economic impacts of alternative greenspace configurations in fast growing cities - the case of Greater Beijing
}

\begin{tabular}{|c|c|}
\hline Journal: & Urban Studies \\
\hline Manuscript ID & CUS-698-17-08.R1 \\
\hline Manuscript Type: & Article \\
\hline $\begin{array}{l}<b>\text { Discipline: Please select a } \\
\text { keyword from the following list } \\
\text { that best describes the } \\
\text { discipline used in your paper.: }\end{array}$ & Planning \\
\hline $\begin{array}{l}\text { World Region: Please select } \\
\text { the region(s) that best reflect } \\
\text { the focus of your paper. } \\
\text { Names of individual countries, } \\
\text { cities \& economic groupings } \\
\text { should appear in the title } \\
\text { where appropriate.: }\end{array}$ & Asia \\
\hline $\begin{array}{l}\text { Major Topic: Please identify up } \\
\text { to } 5 \text { topics that best identify } \\
\text { the subject of your article.: }\end{array}$ & Land Use, Planning, Policy, Transport, Economic Processes \\
\hline $\begin{array}{l}\text { You may add up to } 2 \text { further } \\
\text { relevant keywords of your } \\
\text { choosing below: }\end{array}$ & Urban Modelling, Greenspace \\
\hline
\end{tabular}

\section{SCHOLARONE" \\ Manuscripts}


Economic impacts of alternative greenspace configurations in fast growing cities - the case of Greater Beijing

\begin{abstract}
Greenspaces at the city scale, like greenbelts, green-wedges or green-grids have become wellknown instruments for shaping urban economic activity and land use. The economic impacts of such instruments are complex and hard to measure. This paper addresses one of the rarely studied problems of measuring economic impacts of alternative greenspace configurations in fast growing cities. In such cities, there is an uncertain basis for making such greenspace related decisions, for example the assumptions about the cities' total population and economic activity. Decision makers have few tools to measure and predict the potential economic costs and benefits of alternative greenspace configurations.

We present a new model that allows tracking over time of both non-divisible land use decisions and a multitude of gradual adaptations made by businesses and consumers. The model is applied to Greater Beijing, one of the fast growing cities that is actively exploring alternative greenspace configurations to control urban expansion. The modelling results suggest that compared to the trend-development scenario of no greenspace intervention, a strict greenbelt would decrease the overall consumer surplus in Beijing by $\$ 3.3$ billion, while an adaptive mix of green-wedges and green-grid would increase consumer surplus by $\$ 3.6$ billion per year in 2030 . The adaptive configuration also reduces car journeys by $11 \%$ in Beijing. More generally, modelling results show that a flexible design of strategic greenspaces and careful siting of new development around metro stations within the designated greenspaces could benefit consumers and promote sustainable travel.
\end{abstract}

\title{
Key words
}

Greenspace, Urban Modelling, Recursive Spatial Equilibrium, Land Use Transport Interaction (LUTI), Greater Beijing

\section{Introduction}

Designating large urban greenspaces in planning is a frequently adopted means of land use control. The preserved greenspaces are considered key instruments for protecting the ecosystem, creating amenity and recreational spaces, and preventing undesirable expansion. Urban greenbelt, green-wedges and green-grid are alternative configurations that have been implemented. However, their economic impacts are complex and hard to measure. This is 
because large urban greenspaces will have impacts on multiple urban markets, for example the land market, labour market, product market and transport market. The impacts of greenspaces on each market are hard to quantify without considering the complex and concurrent interactions among these markets. Meanwhile, large urban greenspaces will have enduring impacts on a city's economic wellbeing. Such impacts are hard to trace over time because of the changing historic background conditions.

The greenbelt is the most common strategic greenspace configuration and is implemented in a large number of cities (Amati 2008; Buxton \& Goodman 2003; Kim \& Kim 2008; Okata \& Murayama 2011; Tang et al. 2007; Carter-whitney \& Esakin 2010; Staley et al. 1999). It is considered crucial for shaping compact urban form, stopping urban sprawl (Pendall et al. 2002; Staley et al. 1999) and reducing Vehicle-Miles-Travelled (VMT) (Ewing \& Cervero 2010; Ewing \& Cervero 2017). However, for fast growing cities where development demands keep growing beyond existing masterplans, which is often the case, greenbelts could look, at least to some, anachronistic. In cities where urban growth has exceeded their planned targets, greenbelts have been criticised for increasing land value in the existing city centre (Ball et al. 2014), encouraging car travel (Rodriguez et al. 2006), and increasing urban congestion (Freestone 2002).

The green-wedges policy is an alternative configuration to the greenbelt and has been proposed or implemented in several cities (Cambridge Futures 2000; Knowles 2012). The idea is to allow developments to radiate from the city centre into the designated greenbelt often along public transport corridors, normally at a relatively high net density, such that urban expansion can better integrate with major public investments like rail or metro. The green-grid is another alternative. The idea is to take a bite out of the greenbelt and transform that into a carefully designed plot for development (Rudlin \& Falk 2014). Also, the greengrid idea seeks to connect small pieces of existing greenfield land like small parks and orchards.

Alternative greenspace configurations take a long time to shape. Their governance tends to prefer stability and permanency in their designations. Once they are established, it is very hard to reverse the land use patterns. In fast growing cities, this is problematic. This calls for stronger evidence that can better anticipate different rates of urban expansion. Such a requirement is much tougher than in developed countries with slower growing cities. 
For cities that are reviewing greenbelts and/or initiating alternative configurations, a rigorous tool is needed to measure and predict the potential policy impacts, so that the cost of implementing an unpredictable policy may be avoided. This prompts us to develop a new tool for predicting and comparing the performance of alternatives for fast expanding cities. We aim to answer the following questions: What are the short-term and long-term economic effects of different greenspace configurations? Which configuration performs better in terms of economic efficiency and consumers' wellbeing?

\section{A review of existing methods}

Empirical comparisons were conducted to evaluate the performance of established greenspaces in cities in developed economies (Woo \& Guldmann 2011; Jun 2004; Giuliano \& Narayan 2003; Siedentop et al. 2016). Such studies are based on well-documented data for cross-sectional and cross-city comparisons. For example, Siedentop et al. (2016) compared the land coverage changes of four regions with different levels of greenbelt controls over a decade. However, for cities in emerging economies, such comparisons were hindered by the difficulty in acquiring data.

Partial regression models are commonly used to identify specific economic effects of greenspaces on a single urban market. For example, Lee and Linneman (1998) and Correll et al. (1978) identified amenity value changes as probable consequences from greenbelts or urban growth boundaries. Nelson (1986; 1988), Knaap (1985), Ball et al. (2014) identified land and house price differentials due to land supply constraints. Such studies generally do not specify a model for the housing market in an equilibrium state.

In addition to partial models, feedback and interactions amongst urban markets were established in spatial interaction models, such as in Lee and Fujita (1997), Bae and Jun (2003) and Jun (2011). Lee and Fujita (1997) modelled the interactions among residents, landowners and governments subject to greenbelt locations, and used Herbert-Stevens model for the optimal provision of a greenbelt. Jun (2011) established a random utility-based input-output model with an endogenous land market to test the effects of Seoul's greenbelt on the spatial distribution of population and jobs. 
Existing studies have pointed out that greenspaces will have impacts on multiple urban markets, and due to the multitude of concurrent changes of factors in the whole urban system, it is empirically impossible to isolate one urban market from the others (Wegener 2004). Therefore, whole-city models are needed to test the impacts of greenspaces and to reveal the reciprocal connections between transport and land use (Jun 2004; Rodriguez et al. 2006; Woo \& Guldmann 2011).

Moreover, for modelling fast growing cities, in addition to evaluating policy performance at a particular cross-section or end-state, the time dimension and path dependency of urban development have become important. This is particularly the case for cities that have to modify their growth plans significantly during fast growing phases.

In this light, we develop a new analytical model which can address the interactions amongst various urban markets on a whole-city scale, and the dynamic nature of urban transformations over time. The model will predict the economic impacts of greenspaces on four major urban markets: the day-to-day adaptions of the transport market, the short-to-medium-term impacts on labour and product markets, and the long-term evolution of housing and business floorspace.

\section{The theoretical model}

The analytical model is a new variant of the Land Use and Transport Interaction (LUTI) model, which combines the principles of spatial equilibrium with non-equilibrium urban dynamics. LUTI models have been applied in cities around the world to provide an evidence base for planning decisions. For systematic reviews of LUTI models in application, see articles by Batty (2009), Wegener (2004; 2014), Iacono et al. (2008). For the LUTI model tradition that we follow in this paper, long-term and repeated applications in cities such as Bilbao in Spain, Santiago in Chile, and Cambridge and London in the UK have been effective in supporting the formulation of policies in the last forty years (Research Excellence Framework 2014).

Traditionally, LUTI models assume an equilibrium between supply and demand in the land use and transport markets (Echenique 2011; Williams 1994; Anas \& Liu 2007), while recent development of LUTI models consider the different speeds of urban changes and concentrate on their outcomes over time (Wegener 2004; Simmonds et al. 2013). Based on these substantial contributions, we select a combined equilibrium-recursive structure (Jin et al. 2013) for our model representation, in which the end state of one time period serves as the 
initial state of the subsequent time period: the equilibrium component captures short-tomedium-term adaptions of travel and location choices, while the recursive component follows up long-term development trajectories under different greenspace configurations.

The equilibrium component is developed based on a generic LUTI framework. The land use markets are further developed into two sub-models (see Figure 1; equations are presented in Supplementary Material 1): The Spatial Equilibrium Model, which explores the employmentrelated urban activities; the Non-commuting Travel Demand Model, which explores the noncommuting urban activities.

The Spatial Equilibrium Model (built in Matlab scripts following the RELU-TRAN structure) predicts the employment and residential locations under a simultaneous equilibrium in the production market, labour market and real estate market. The core of this sub-model includes a hybrid Cobb-Douglas Constant Elasticity of Substitution (CES) functions for producer choices for production inputs and consumer choices for consumption (Anas \& Liu 2007; Anas \& Rhee 2006; Jin et al. 2013). It predicts employment-residence locations based on a logit form discrete choice model, which facilitates the non-commuting activity generation and transport demand estimation. It also offers the starting point of the development trajectories and defines the inertias and trends for the next decade.

The Non-commuting Travel Demand Model (built in the MEPLAN-LUS module) takes the prediction of employment-residence locations from the Spatial Equilibrium Model, and predicts locations of non-commuting urban activities based on an input-output social accounting matrix and market constraints. It generates non-commuting travel demand for the transport simulation.

The transport market is represented by a Strategic Transport Model, which is a trip-based model. This model is built in the MEPLAN-TAS module. It takes the travel demands, namely trip ends, from the two land use sub-models, splits traffic flows into travel modes, and assigns them on the transport network. By doing this, it gives the travel disutilities between origindestination (OD) zone pairs back to the two land use sub-models, which is the bridge for land-use and transport interaction.

The Spatial Equilibrium Model, Non-commuting Travel Demand Model, and Strategic Transport Model form the equilibrium component and represent one cross-sectional year of simulation. The Recursive Dynamic Model (built in Matlab script, following the MEPLANLUS structure) links several cross-sectional years and updates the floorspace supply and 
transport network for the next cross-sectional year, based on endogenous outputs from the spatial equilibrium component that represents market inertia and exogenous policy interventions.

The modelling package starts with a cross-sectional base year run. In the base year, the model runs under calibration mode. It receives two main inputs: the quantities of housing and business floorspace, and the travel disutilities between all OD zone pairs. Model predictions (numbers of jobs, residents, production value, demands for floorspace, rents and wages) are compared with known zonal quantities and prices from published statistics, such as censuses and travel surveys, to refine the parameters. The parameters are validated and re-estimated. The validation requires a second observed cross-sectional year to test the suitability of the calibrated parameters. After validation, the parameters are then used for prediction.

The model outputs show the zonal average economic productivity, household utility and travel behaviour by socio-economic group under alternative greenspace configurations. The main outputs include zonal population and employment numbers, rents, household utility by socio-economic group, the floorspace stock, travel times, distances and costs by socioeconomic group and by travel purpose, and the travel mode share. The outputs provide a consistent basis for comparing economic impacts of alternative greenspace configurations.

\section{[INSERT FIGURE 1 HERE]}

\section{Model application - which greenspace configuration for Greater Beijing in 2030?}

We test the theoretical model on one of the fastest growing cities - Greater Beijing. It is a typical example of a fast growing city which intends to establish strategic greenspaces to achieve environmental benefits and control undesirable urban expansion.

\section{Policy context and geographical specification}

Beijing introduced its first greenbelt in 1994 in order to stop the successive urban expansion wave. The second greenbelt was introduced in 2003 and emphasised the latest Beijing Masterplan of 2016 - 2035. Studies have shown that Beijing's greenbelt policies increased tree canopy cover (Yang \& Zhou 2007), encouraged tree planting on village brownfield (Tan 
2008), preserved the continuity of large pieces of greenspaces (Gan 2012), and safeguarded water bodies and forest (Han \& Long 2010).

The establishment of greenbelts are well-grounded by their environment benefits, but the promoters were frustrated by the difficulties in policy implementation. In fact, data show that the percentage of greenfield land remaining from the proposed first greenbelt is less than $11 \%$ (Wang 2015). In the second greenbelt, land that is available for greenery reduced from 412 $\mathrm{km}^{2}$ in 2002 to $163 \mathrm{~km}^{2}$ in 2007 (Beijing Municipal Commission of Urban Planning 2007). The setback is attributed to weak planning regulation (Yang 2008; Han \& Long 2010). However, there is a lack of research and a gap in understanding and measuring the economic impacts of greenbelts. In the revision of current greenbelt policy, planners have proposed an alternative configuration that breaks greenbelt into green-wedges and green-grid (Beijing Urban Planning and Design Institute 2007; Beijing Municipal Government 2017). Their economic impacts have not yet been rigorously tested either.

In order to mitigate the overconcentration of business activities and population in Beijing, the national government has launched a Master Plan of Beijing-Tianjin-Hebei Integrated Development in 2015 (Central Political Bureau of China \& The State Council 2015). This plan emphasises that regional integration is crucial for tackling the perceived overcrowding in Beijing. Expressways and high-speed railway projects have been proposed to facilitate the redistribution of economic activities and population, but there are few exiting tools to understand and measure the effects of such strategic plans.

In order to include all relevant land use activities and transport flows within the megacity region, both for the present spatial extent and for the expected future expansion, our Greater Beijing Model includes Beijing Municipality, Tianjin Municipality and Hebei Province. The model zoning at the level of local cities and counties allows the effects of strategic greenspace scenarios to be assessed at a level that is consistent with local governance for investment and regulation, as well as for region-wide coordination.

The region is divided into 209 zones according to the existing administrative boundaries and transport links. Beijing Municipality is divided into 130 zones with a detailed road network. Out of the 130 zones, 28 zones at Beijing's urban fringe are selected as greenbelt zones for policy test purposes. A greenbelt zone may turn into a built-up zone, be preserved as the greenbelt, or a zone with multiple Transit Oriented Development (TOD) nodes. For a zone with TOD nodes, development takes place around each station in relatively high net density, 
and both housing and business floorspace are allowed following the Density-DiversityDesign principle (Ewing \& Cervero 2010). These areas are expected to yield low vehicle ownership, high transit and walking mode shares on work trips and short drive times to work (Cervero 2015; Ewing \& Cervero 2010; Cao \& Chatman 2016; Ewing \& Cervero 2017).

We further classify the 130 zones in Beijing Municipality into 6 categories: 1) the central city, 2) the inner city, 3) the greenbelt zones, 4) the new towns, 5) the far suburb and 6) the ecological protection area (EPA).

[INSERT FIGURE 2 HERE]

\section{Greenspace scenarios}

Based on the existing plans and the historical development trends, we classify three greenspace configurations from 2010 to 2030: 1) Beijing's past expansion has pointed to the concentric growth as the default Trend development scenario, which means no specific greenspace intervention will be implemented. 2) Despite the fragmented remaining greenspaces, there are appeals for no more development in the designated second greenbelt (Beijing Municipal Government 2008; Beijing Municipal Commission of Urban Planning 2012). Therefore, the Greenbelt is the second scenario. 3) As the mixed greenspace configuration has been proposed in the latest masterplan, we test it as the third scenario, called Green-grid. In this scenario, parts of the greenbelt will be gradually built-up, and the ring-shaped greenbelt will evolve to wedges then to a grid over time. The selected built-up areas are those with metro or train services. Such built-up areas are TOD nodes. Figure 3 is a diagram that illustrates the three scenarios.

\section{[INSERT FIGURE 3 HERE]}

The three scenarios are based on the same projections of regional macroeconomic and demographic growth. That is to say, they share the same overall assumptions of total number of population, same regional floorspace stock, and same future road and metro networks as set in the governments' development and infrastructure plan. Metro capacity and fare stay the 


\section{[INSERT TABLE 1 HERE]}

\section{Model calibration and specification for forecasts}

A well-calibrated base year is fundamental for the accuracy of future predictions. The predictive capability of LUTI models is assessed through whether a model can reproduce the current (or historical) situation as represented by the data on that situation (Wilson 1998). The Greater Beijing model is established based on cross-sectional data for three decades, namely 1990, 2000, 2010. The model is calibrated for year 2010, and validated through reproducing year 1990 and 2000 . The multiple cross-section validation ensures that model is 
well structured and calibrated for predicting medium to long term trends (Wan \& Jin 2017). Parameters and data inputs for calibration are reported in Supplementary Material 2.

We then run the model from year 2010 to year $2030^{1}$, based on the following segmentations: 3 social-economic groups (high, medium, low) segmented according to their income levels and jobs; 5 travel modes (car, bus, walk, cycle, metro/rail); 4 travel purposes (commuting, education, business, other) in line with the transport survey in Beijing.

\section{Results}

Aggregate modelling results on Beijing municipal level. The aggregate level modelling results show that greenspace interventions will have a wider impact beyond Beijing Municipality onto the entire region. Compared to the Trend scenario, both Greenbelt and Green-grid stimulate a relocation of population and jobs from Beijing to its surrounding areas. The magnitude of the relocation is more obvious with the implementation of the strict greenbelt. The Greenbelt scenario has the least housing provision. The shortage of floorspace pushes rent up by $7 \%$ for housing and $3 \%$ for business floorspace, despite the shrinking demands due to the decrease of population and employment in Beijing.

\section{[INSERT TABLE 2 HERE]}

Localised results. Compared to Trend, the greenbelt zones lose more than half of the residents and jobs in the Greenbelt scenario (see Figure 4). People move from the greenbelt to the inner city, instead of new towns in the far suburb. While people concentrate in the centre, there is no added employment. Jobs are pushed further from the greenbelt to the wider southeast transport corridor towards Tianjin.

\footnotetext{
${ }^{1}$ In order to highlight the difference between the traditional static model and our recursive model, we did both a static run and a recursive run from 2010 to 2030. Supplementary Material 3 provides a comparison between the two modelling methods.
} 
The impacts of Green-grid are relatively local within the urban fringe. With the sheer drop of the number of residents in the preserved greenbelt zones, TOD nodes become popular. Number of jobs also increases in TOD nodes to achieve work-home balance.

\section{[INSERT FIGURE 4 HERE]}

Figure 5 shows the variations in housing floorspace supply and rent. Under the greenbelt restriction, the floorspace supply in the greenbelt is remarkably low. Meanwhile, because less people live in the greenbelt, the shrinking demand brings down housing rent by about $10 \%$. Housing rent in the rest of Beijing goes up in general and the rent in the city centre increases by $13 \%$. Note that the amenity value of the greenbelt is not modelled explicitly; instead, it is included in the residual attractiveness $E_{f i j}$ (see Supplementary Material 1, Equation 2). The residuals are empirically calibrated for 2010 , so any potential increase of amenity value from 2010 to 2030 may be underestimated, and thus the magnitude of rent decrease in greenbelt zones may be overestimated. In Green-grid, the TOD nodes become popular primarily because of the sufficient floorspace supply. Most of the nodes see a more than $50 \%$ increase in housing supply and rent increases accordingly because of the rising demand.

\section{[INSERT FIGURE 5 HERE]}

Table 3 reports the transport modelling results. On the regional level, a reduction of VMT can be observed in the Green-grid scenario. For Beijing Municipality and its urban fringe, mode choice shifts from car to non-vehicle and public transport can also be observed. The overall mode choice shift is due to the work-home balance in TOD nodes. As people work locally, intra-zonal commuting is promoted where car is uneconomic: intra-zonal journeys are in general shorter than inter-zonal journeys, so off-network travel time and parking fee $\left(p_{j m}^{t}\right.$ in Equation 8) account for a larger proportion in the generalised travel costs in car journeys, which reduce the advantages of cars compared to other modes. Additionally, for TOD nodes, 
development takes place around stations so that the access time to public transport is shorter, which promotes metro mode share.

\section{[INSERT TABLE 3 HERE]}

Figure 6 reports variations in consumption utility among scenarios. Utility is determined by two factors: how much floorspace a household can afford to rent and how many goods they can buy. Under the Trend scenario, due to the high rent in Beijing, the utility level in Beijing (6.40) is generally lower than its surrounding areas (6.75 regional average), and the inner city is even lower due to the high price level. The Greenbelt scenario fails to improve the consumption utility for most zones, as the average utility drops to 6.38. The designated greenbelt area is an exception. With the decrease of population and the drop in rent, the greenbelt turns into an affordable area at the cost of making the rest of Beijing more expensive. In Green-grid, consumption utility witnesses an overall increase in Beijing to 6.42, with the exceptions of a limited number of TOD nodes and suburban zones. Under Greengrid, the total residents decrease by $2 \%$ in Beijing while housing supply remains the same. The shrinking demand brings rent down by $1 \%$. Moreover, the average commuting distance decreases from $13.6 \mathrm{~km}$ in Trend to $13.1 \mathrm{~km}$, mainly because more people work locally, and the access distance to stations are shorter.

When we convert the utility into monetary terms by Equation 12, the drop of utility in Greenbelt equals a loss of $\$ 349$ per employed resident per year, which equals $\$ 3.3$ billion for the whole municipality. This drop accounts for $1.56 \%$ total household disposable income. In Green-grid, the increase of utility equals $\$ 385$ per employed resident, which means Beijing gains $\$ 3.6$ billion. This increase accounts for $1.72 \%$ total household disposable income.

\section{[INSERT FIGURE 6 HERE]}

\section{Discussions and conclusions}

In the context of the policy goal for regional integration, the modelling results highlight the significant geographic variations of impacts. A strict control of the greenbelt will relocate $6 \%$ 
of the population from Beijing to Tianjin and Hebei, which at the face value may be considered a positive contribution to relieving overcrowding in Beijing. However, on closer look, under the current inter-city transport plan, the greenbelt will concentrate more employed residents ( 0.55 million) in Beijing's city centre. In this sense, the strict greenbelt may not relieve overcrowding where the growth pressures are the highest, and could even exacerbate it.

The model results help to pinpoint where the growth pressures are highest under a given scenario. For example, the Beisanxian County (refer to Figure 2) stands out as facing high pressures for housing development and employment growth under Trend and Greenbelt scenarios. Such findings could prompt planners to further investigate the potentials of transport investment to connect Beijing and Beisanxian to promote intercity-commuting and relieve overcrowding.

From a local perspective, a greenbelt is unlikely to be the highest performing intervention for Beijing's economic wellbeing. The negative effects of the greenbelt, such as less housing supply (11\% lower than Trend), higher housing rent (7\% higher than Trend), lower productivity ( $3 \%$ lower than Trend), and a decrease in consumption utility $(0.3 \%$ lower than Trend) would weaken the leading role of Beijing in the city region. Although Beijing's greenbelts have been extensively studied in terms of environmental benefits (Yang \& Zhou 2007; Tan 2008; Gan 2012; Han \& Long 2010), the findings here indicate that their economic impacts should be studied in more depth. In future strategic greenspace design, the economic as well as environmental effects should be considered. Also, it might be difficult to achieve both environmental and economic benefits through a single greenbelt policy. The possibility of combining greenbelts with other policies, for example congestion tolls (Anas \& Rhee 2006) could be considered and tested using tools like this model.

The green-grid, which stands for a flexible and mixed greenspace configuration, would appear to be an option that better balances economic efficiency and environmental benefits in terms of reducing car usage. Building around metro/rail stations at a relatively high density benefits local residents, as consumption utility sees an overall increase. Compared to Trend, journeys on public transport increase by $28 \%$ and active travel by $57 \%$, while those using cars are down by a third at the urban fringe. Such findings are in line with the previous studies (Cervero 2015; Ewing \& Cervero 2010; Cao \& Chatman 2016; Ewing \& Cervero 2017). However, our model also finds that housing and business floorspace rents increase in 
TOD nodes. This indicates that the design of TOD nodes needs to account for such effects and might need to combine other policies to secure floorspace supply.

As the land use demand changes rapidly in Beijing, it appears to be beneficial for policy makers to periodically review where should be relaxed in the designated greenbelt, and to allow patches of land to be developed in certain areas. Such sites need to be carefully selected around metro stations to accommodate the forthcoming growth. More generally, a flexible design of greenspace configurations and a careful siting of new development in the designated greenbelt area could bring potential benefits to residents' wellbeing.

This model provides a systematic analytical platform for predicting, comparing and analysing the performance of alternative greenspace configurations over time. Under rapid urban transformation, large scale greenspace policies need to be reviewed constantly using tools such as that presented in this research. On the one hand, urban greenspaces need to be implemented as firm designations in order to enhance the environment quality. On the other hand, under fast growing conditions, the population sizes and land use needs may radically change from assumptions previously made. It can be beneficial to modify the existing greenspace configurations in line with the new contexts of urban development. This is a difficult call for decision makers, and the new model will help to shed light on the potential economic costs and benefits between the alternative propositions.

This paper presents a strategic study on examining the economic impacts of greenspaces. The model works on aggregated zones, which makes measuring the sub-zonal level proximity to greenspaces difficult. Also, there is no explicit agency of government or developer, so it is difficult to accurately test the impacts of greenspaces in combination of other policies related to such agencies. Moreover, the model does not develop a platform for comparing the economic costs to the environmental benefits of greenspaces. Instead, it intends to emphasise the importance of assessing economic impacts in decision making process. In the future, the spatial granularity of the model needs be improved and more agencies could be added when data are available to improve the model's realism. The model could interface with micro simulation models to improve the representation of consumer and producer's behaviour. The model can also interface with other models that are specialised in quantifying environmental impacts to generate a more complete picture to assist decision making.

\section{References}

Anas, A. \& Liu, Y., 2007. A Regional Economy, Land Use, and Transportation Model (Relu- 
Tran): Formulation, Algorithm Design, and Testing. Journal of Regional Science, 47(3), pp.415-455.

Anas, A. \& Rhee, H.-J., 2006. Curbing excess sprawl with congestion tolls and urban boundaries. Regional Science and Urban Economics, 36(4), pp.510-541.

Bae, C.-H.C. \& Jun, M.-J., 2003. Counterfactual Planning: What if there had been No Greenbelt in Seoul? Journal of Planning Education and Research, 22(4), pp.374-383.

Ball, M. et al., 2014. Urban Growth Boundaries and their impact on land prices. Environment and Planning A, 46, pp.3010-3026.

Batty, M., 2009. Urban Modelling. In N. Thrift \& R. Kitchin, eds. International Encyclopedia of Human Geography. Oxford: Elsevier, pp. 51-58.

Beijing Municipal Commission of Urban Planning, 2012. Beijing Main Functional Zone Plan, China.

Beijing Municipal Commission of Urban Planning, 2007. Comments on the Planning and Implementation of the Second Greenbelt. Beijing Planning Review, (6).

Beijing Municipal Government, 2008. [2008] No 17 The Approavel from Beijing Municipal Government on the Proposal from Beijing Municipal Commission of Development and Reform Regarding the First Greenbelt Plan, China.

Beijing Municipal Government, 2017. The Beijing Masterlan 2016 -2035,

Beijing Urban Planning and Design Institute, 2007. The Plan of the Green System in Beijing, China.

Cambridge Futures, 2000. Cambridge Futures 1. Available at: http://www.cambridgefutures.org/futures1/intro.htm [Accessed July 12, 2016].

Cao, X. \& Chatman, D., 2016. How will smart growth land-use policies affect travel? A theoretical discussion on the importance of residential sorting. Environment and Planning B: Planning and Design, 43(1), pp.58-73.

Central Political Bureau of China \& The State Council, 2015. Master Plan of Beijing-TianjinHebei Integrated Development,

Cervero, R., 2015. Transit-oriented development and the urban fabric. In B. Loo \& C. Comtois, eds. Sustainable Railway Futures. pp. 75-93. 
Correll, M.R., Lillydahl, J.H. \& Singell, L.D., 1978. The effects of greenbelts on residential property values: some findings on the political economy of open space. Land economics, 54(2), pp.207-217.

Echenique, M., 2011. Land use/transport models and economic assessment. Research in Transportation Economics, 31(1), pp.45-54.

Ewing, R. \& Cervero, R., 2017. "Does Compact Development Make People Drive Less?" The Answer Is Yes. Journal of the American Planning Association, 83(1), pp.19-25.

Ewing, R. \& Cervero, R., 2010. Travel and the built environment. Journal of the American Planning Association, 76(3), pp.265-294.

Freestone, R., 2002. Greenbelts in city and regional planning. In K. c. Parsons \& D. Schuyler, eds. From garden city to green city: the legacy of Ebenezer Howard. pp. 67-98.

Gan, L., 2012. Analyses of the effects of Beijing's greenbelts based on remote sensing images. Beijing Planning Review, (5), pp.37-40.

Giuliano, G. \& Narayan, D., 2003. Another look at travel patterns and urban form: The US and Great Britain. Urban Studies, 40(11), pp.2295-2312.

Han, H. \& Long, Y., 2010. Research on the effects of the first greenbelt in Beijing. Beijing Planning Review, 3, pp.59-63.

Holroyd, E.M., 1966. Theoretical Average Journey Lengths in Circular Towns with Various Routeing Systems. Road Research Laboratory Report No. 43 Ministry of Transport.

Iacono, M., Levinson, D. \& El-Geneidy, A., 2008. Models of Transportation and Land Use Change: A Guide to the Territory. Journal of Planning Literature, 22(4), pp.323-340.

Jin, Y. et al., 2017. Environmental impacts of transformative land use and transport developments in the Greater Beijing Region: Insights from a new dynamic spatial equilibrium model. Transportation Research Part D: Transport and Environment, 52, pp.548-561.

Jin, Y., Echenique, M. \& Hargreaves, A.J., 2013. A recursive spatial equilibrium model for planning large-scale urban change. Environment and Planning B: Planning and Design, 40(6), pp.1027-1050.

Jun, M.-J., 2004. The effects of Portland's urban growth boundary on urban development 
patterns and commuting. Urban Studies, 41(7), pp.1333-1348.

Jun, M.-J., 2011. The effects of Seoul's greenbelt on the spatial distribution of population and employment, and on the real estate market. The Annals of Regional Science, 49(3), pp.619-642.

Knaap, J., 1985. The Price Effects of Urban Growth in Metropolitan Portland, Oregon Gerrit. Land economics, 61(1), pp.26-35.

Knowles, R.D., 2012. Transit Oriented Development in Copenhagen, Denmark: From the Finger Plan to Orestad. Journal of Transport Geography, 22, pp.251-261.

Lee, C.-M. \& Fujita, M., 1997. Efficient configuration of a greenbelt. Environment and Planning A, 29(7), pp.1999-2017.

Lee, C.-M. \& Linneman, P., 1998. Dynamics of the greenbelt amenity effect on the land market. real estate economics, 26(1), pp.107-129.

Ma, M., 2017. Are There Alternatives to Greenbelts? Evidence from a New Land-use Transport Interaction Model for Greater Beijing. Doctoral Thesis, University of Cambridge.

Nelson, A.C., 1988. An empirical note on how regional urban containment policy influences an interaction between greenbelt and exurban land markets. Journal of the American Planning Association, (December 2012), pp.37-41.

Nelson, A.C., 1986. Using Land Markets to Evaluate Urban Containment Programs. Journal of the American Planning Association, 52(2), pp.156-171.

Pendall, R., Martin, J. \& Fulton, W., 2002. Holding the line: urban containment in the United States., (August), p.51.

Rodriguez, D.A., Targa, F. \& Aytur, S.A., 2006. Transport Implications of Urban Containment Policies: A Study of the Largest Twenty-five US Metropolitan Areas. Urban Studies, 43(10), pp.1879-1897.

Rudlin, D. \& Falk, N., 2014. Uxcester Garden City: Second Stage Submission for the 2014 Wolfson Economics Prize,

Siedentop, S., Fina, S. \& Krehl, A., 2016. Greenbelts in Germany's regional plans-An effective growth management policy? Landscape and Urban Planning, 145, pp.71-82. 
Simmonds, D., Waddell, P. \& Wegener, M., 2013. Equilibrium versus dynamics in urban modelling. Environment and Planning B: Planning and Design, 40(6), pp.1051-1070.

Staley, S., Edgens, J. \& Mildner, G., 1999. A line in the land: Urban-growth boundaries, smart growth, and housing affordability,

Tan, Q., 2008. Investigation and Exploration of Beijing Green Belt Planning - A Case Study of Sijiqing Township. Master Degree Thesis, Tsinghua University.

Wan, L. \& Jin, Y., 2017. Assessment of model validation outcomes of a new recursive spatial equilibrium model for the Greater Beijing. Environment and Planning B: Urban Analytics and City Science, pp.1-21.

Wang, K., 2015. Beijing-Tianjin-Hebei Coordinating Development Under New Normality. In Conference proceedings of China Annual National Planning Conference 2015.

Wegener, M., 2014. Land-Use Transport Interaction Models. In M. Fischer \& P. Nijkamp, eds. Handbook of Regional Science. Springer, Heidelberg, pp. 741-758.

Wegener, M., 2004. Overview of land-use transport models. In D. A. Hensher \& K. Button, eds. Transport geography and spatial systems. Kidlington: Pergamon/Elsevier Science, pp. 127-146.

Williams, I., 1994. A model of London and the South East. Environment and Planning B: Planning and Design, 21(5), pp.535-553.

Wilson, A., 1998. Land-use/transport interaction models: Past and future. Journal of Transport Economics and Policy, 32(1), pp.3-26.

Woo, M. \& Guldmann, J.-M., 2011. Impacts of Urban Containment Policies on the Spatial Structure of US Metropolitan Areas. Urban Studies, 48(16), pp.3511-3536.

Yang, J. \& Zhou, J., 2007. The failure and success of greenbelt program in Beijing. Urban Forestry and Urban Greening, 6, pp.287-296.

Yang, X., 2008. Research of Beijing's Greenbelt Policy: History Review, Implementation and Problems. Tsinghua University. 
Table 1 Locations of floorspace development

\begin{tabular}{|c|c|c|c|c|c|c|c|c|}
\hline \multirow[t]{2}{*}{ Scenarios } & \multicolumn{6}{|c|}{ Locations of floorspace development } & \multicolumn{2}{|c|}{$\begin{array}{c}\text { Proximity to transport } \\
\text { network }\end{array}$} \\
\hline & U⿺辶ِّ & 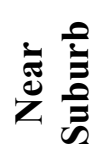 & 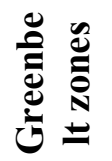 & $\hat{\theta} \underset{0}{0}$ & 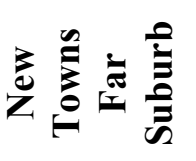 & $\frac{\pi}{a}$ & $\begin{array}{l}\text { Road access } \\
\text { link length }\end{array}$ & $\begin{array}{c}\text { Station } \\
\text { access link } \\
\text { length }\end{array}$ \\
\hline 1 Trend & $x$ & $\sqrt{ }$ & $\sqrt{ }$ & $\mathrm{N} / \mathrm{A}$ & $\sqrt{ }$ & $x$ & $93 \% \mathrm{r}$ & $86 \% \mathrm{r}$ \\
\hline $\begin{array}{c}2 \\
\text { Greenbelt }\end{array}$ & $\times$ & $\sqrt{ }$ & 0 & N/A & $\sqrt{ }$ & $x$ & $100 \% \mathrm{r}$ & $114 \% \mathrm{r}$ \\
\hline \multirow{2}{*}{$\begin{array}{l}3 \text { Green- } \\
\text { grid }\end{array}$} & \multirow{2}{*}{\multicolumn{2}{|c|}{$\times$}} & \multirow[t]{2}{*}{0} & \multirow[t]{2}{*}{$\sqrt{+}$} & \multirow[t]{2}{*}{$\sqrt{ }$} & \multirow[t]{2}{*}{$x$} & \multicolumn{2}{|c|}{$\begin{array}{l}\text { Same as scenario } 2 \text { except } \\
\text { for TOD nodes, where }\end{array}$} \\
\hline & & & & & & & $96 \% \mathrm{r}$ & $58 \% \mathrm{r}$ \\
\hline Note & \multicolumn{8}{|c|}{ 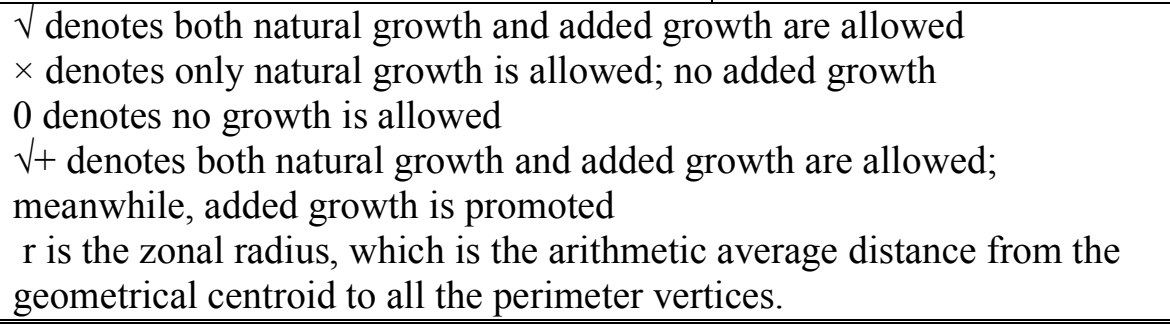 } \\
\hline
\end{tabular}

Model calibration and specification for forecasts

Table 2 Aggregate modelling results on Beijing municipal level

\begin{tabular}{|c|c|c|c|}
\hline & 1 Trend & $\begin{array}{c}2 \\
\text { Greenbelt* }\end{array}$ & 3 Green-grid* \\
\hline Employed residents (Thousand people) & 18887 & $-6 \%$ & $-2 \%$ \\
\hline Employed workers (Thousand people) & 18980 & $-6 \%$ & $-2 \%$ \\
\hline Housing floorspace supply (million $\mathrm{m}^{2}$ ) & 1169 & $-11 \%$ & $0 \%$ \\
\hline \multicolumn{4}{|l|}{ Housing floorspace within the originally } \\
\hline $\begin{array}{c}\text { designated greenbelt zones in } 2030 \\
\left(\text { million } \mathbf{~ m}^{2}\right)\end{array}$ & 330 & $-42 \%$ & $-1 \%$ \\
\hline Business floorspace supply (million $\mathbf{m}^{2}$ ) & 461 & $-4 \%$ & $0 \%$ \\
\hline \multicolumn{4}{|l|}{ Business floorspace within the originally } \\
\hline $\begin{array}{l}\text { designated greenbelt zones in } 2030 \\
\left.\text { (million } \mathbf{~ m}^{2}\right)\end{array}$ & 107 & $-41 \%$ & $9 \%$ \\
\hline Average housing rent $\left(\$ / \mathbf{m}^{2} /\right.$ year $)$ & 194 & $7 \%$ & $-1 \%$ \\
\hline $\begin{array}{c}\text { Average business floorspace rent (\$ } \\
/ \mathrm{m}^{2} / \text { year) }\end{array}$ & 81 & $3 \%$ & $-2 \%$ \\
\hline $\begin{array}{l}\text { Total production in quantity of } \\
\text { composite goods (millions) }\end{array}$ & 5687 & $-3 \%$ & $-2 \%$ \\
\hline
\end{tabular}


Table 3 Main transport modelling results

\begin{tabular}{|c|c|c|c|}
\hline & 1 Trend & 2 Greenbelt & 3 Green-grid \\
\hline \multicolumn{4}{|c|}{ Vehicle miles travelled in Beijing-Tianjin-Hebei Region } \\
\hline $\begin{array}{c}\text { Passenger miles travelled per person } \\
\text { per year }\end{array}$ & 6994 & 6989 & 6893 \\
\hline $\begin{array}{c}\text { Vehicle miles travelled per person per } \\
\text { year }\end{array}$ & 3282 & 3247 & 3148 \\
\hline \multicolumn{4}{|c|}{ Commuting trips in Beijing } \\
\hline Average commuting distance & 13.6 & 13.3 & 13.1 \\
\hline Trips by car (thousand trips) & $\begin{array}{l}9108 \\
(58 \%)\end{array}$ & $8443(57 \%)$ & $8097(52 \%)$ \\
\hline $\begin{array}{l}\text { Trips by non-vehicle modes (thousand } \\
\text { trips) }\end{array}$ & $\begin{array}{l}1864 \\
(12 \%)\end{array}$ & $1795(12 \%)$ & $2126(14 \%)$ \\
\hline $\begin{array}{c}\text { Trips by public transport (thousand } \\
\text { trips) }\end{array}$ & $\begin{array}{c}4753 \\
(30 \%) \\
\end{array}$ & $4546(31 \%)$ & $5191(34 \%)$ \\
\hline \multicolumn{4}{|c|}{ Commuting trips in greenbelt zones } \\
\hline Trips by car (thousand trips) & $\begin{array}{c}2552 \\
(60 \%)\end{array}$ & $1365(62 \%)$ & $1686(42 \%)$ \\
\hline $\begin{array}{c}\text { Trips by non-vehicle modes (thousand } \\
\text { trips) }\end{array}$ & $489(12 \%)$ & $221(10 \%)$ & $766(19 \%)$ \\
\hline $\begin{array}{c}\text { Trips by public transport (thousand } \\
\text { trips) }\end{array}$ & $\begin{array}{l}1204 \\
(28 \%)\end{array}$ & $631(28 \%)$ & $1541(39 \%)$ \\
\hline
\end{tabular}


Figure 1 Modelling structure

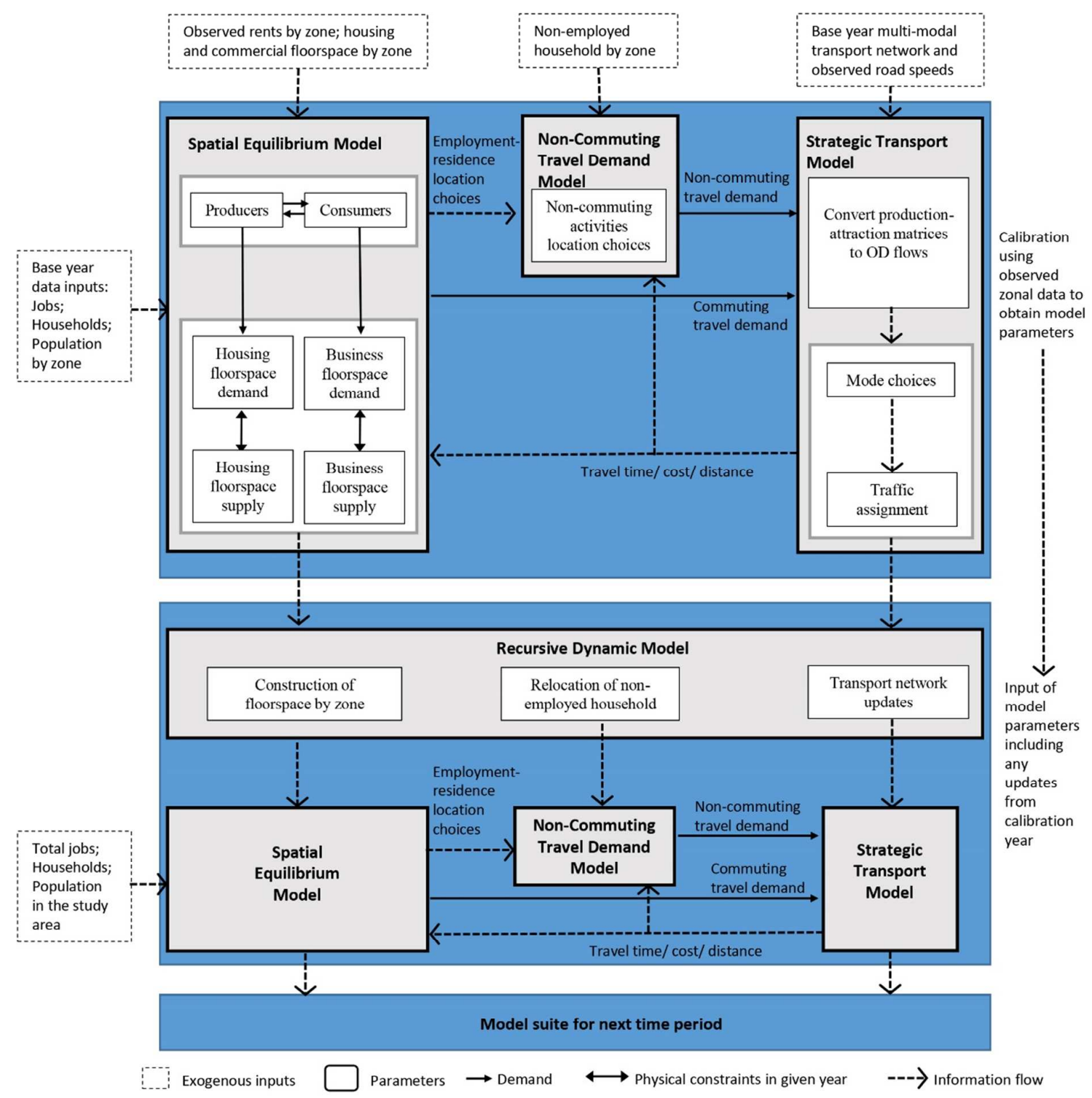


Figure 2 Geographical extent (left) and zone categories in Beijing (right)

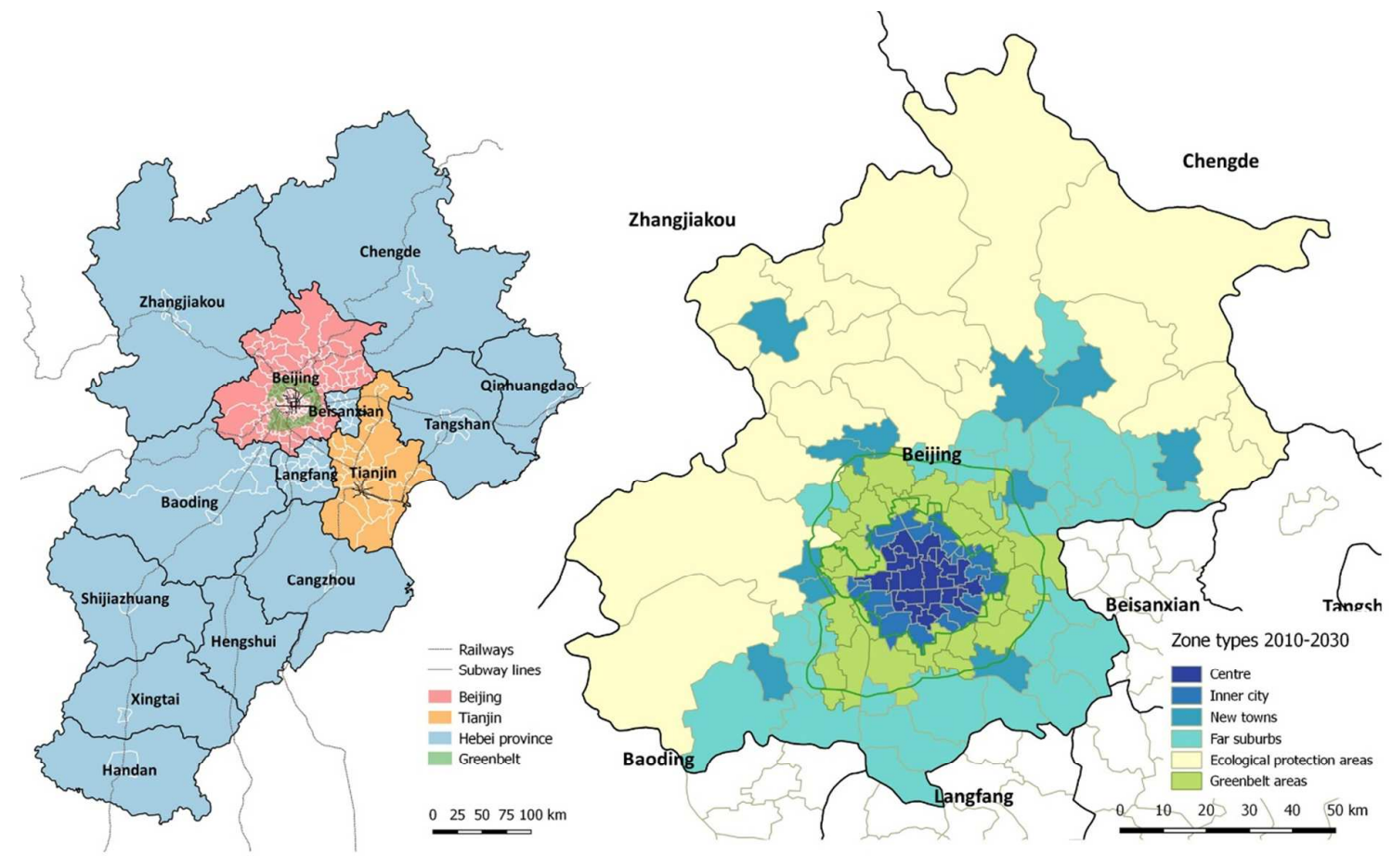


Figure 3 Scenarios of greenspace configurations

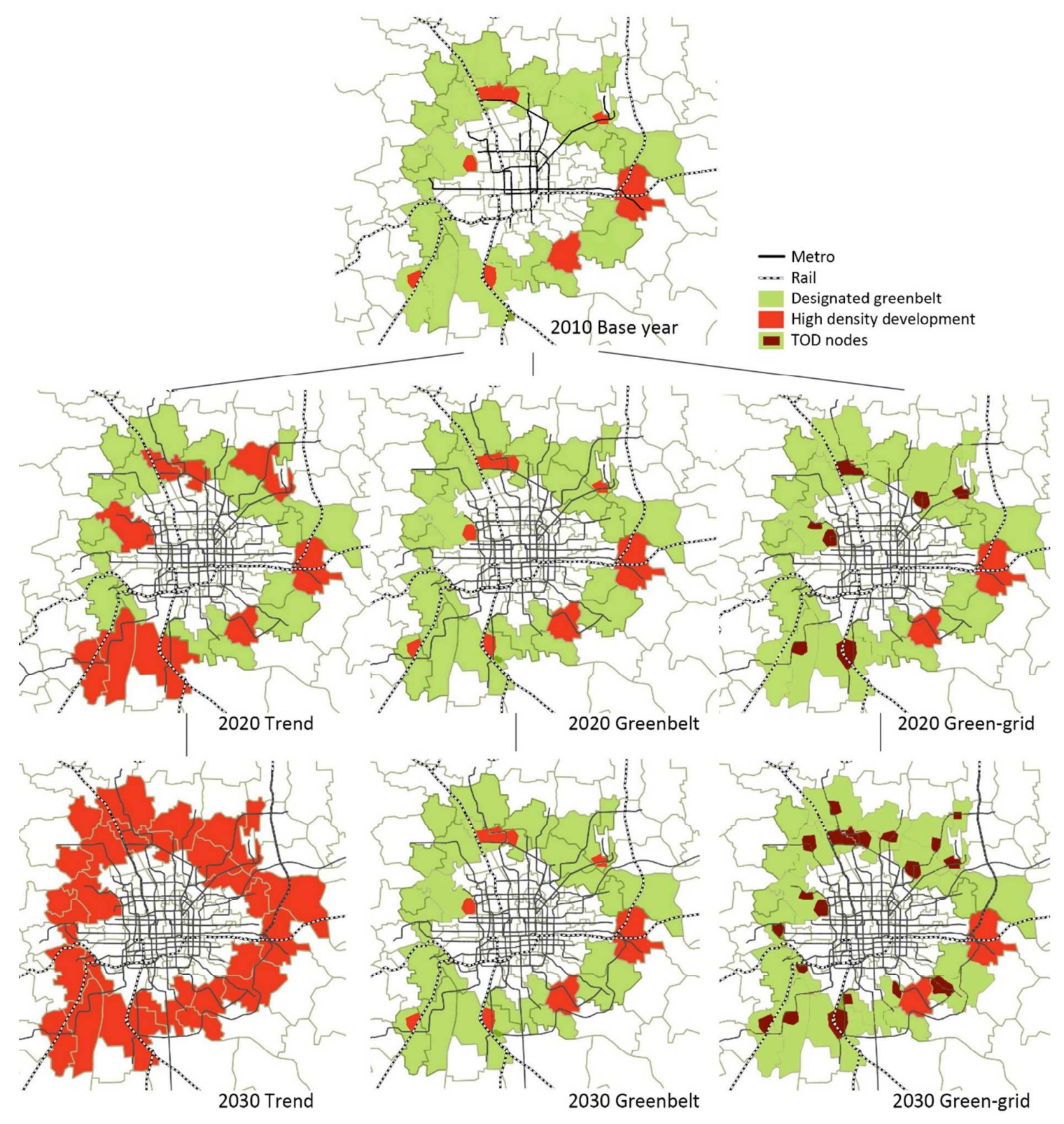


Figure 4 Distribution of employed residents and workers in Trend, and the changes in Greenbelt/Green-grid compared to Trend
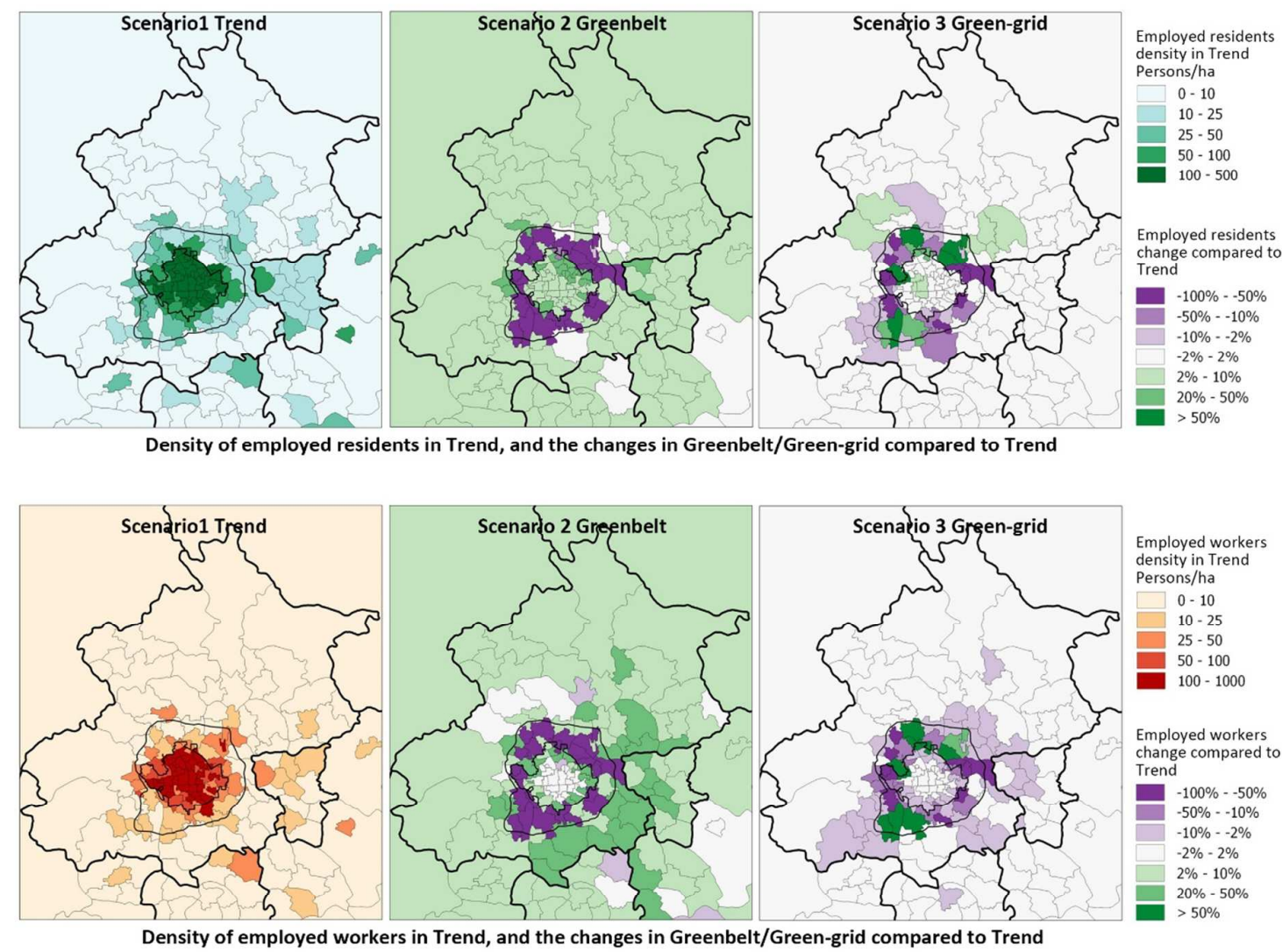
Figure 5 Housing floorspace density and rent in Trend, and the changes in Greenbelt/Greengrid compared to Trend
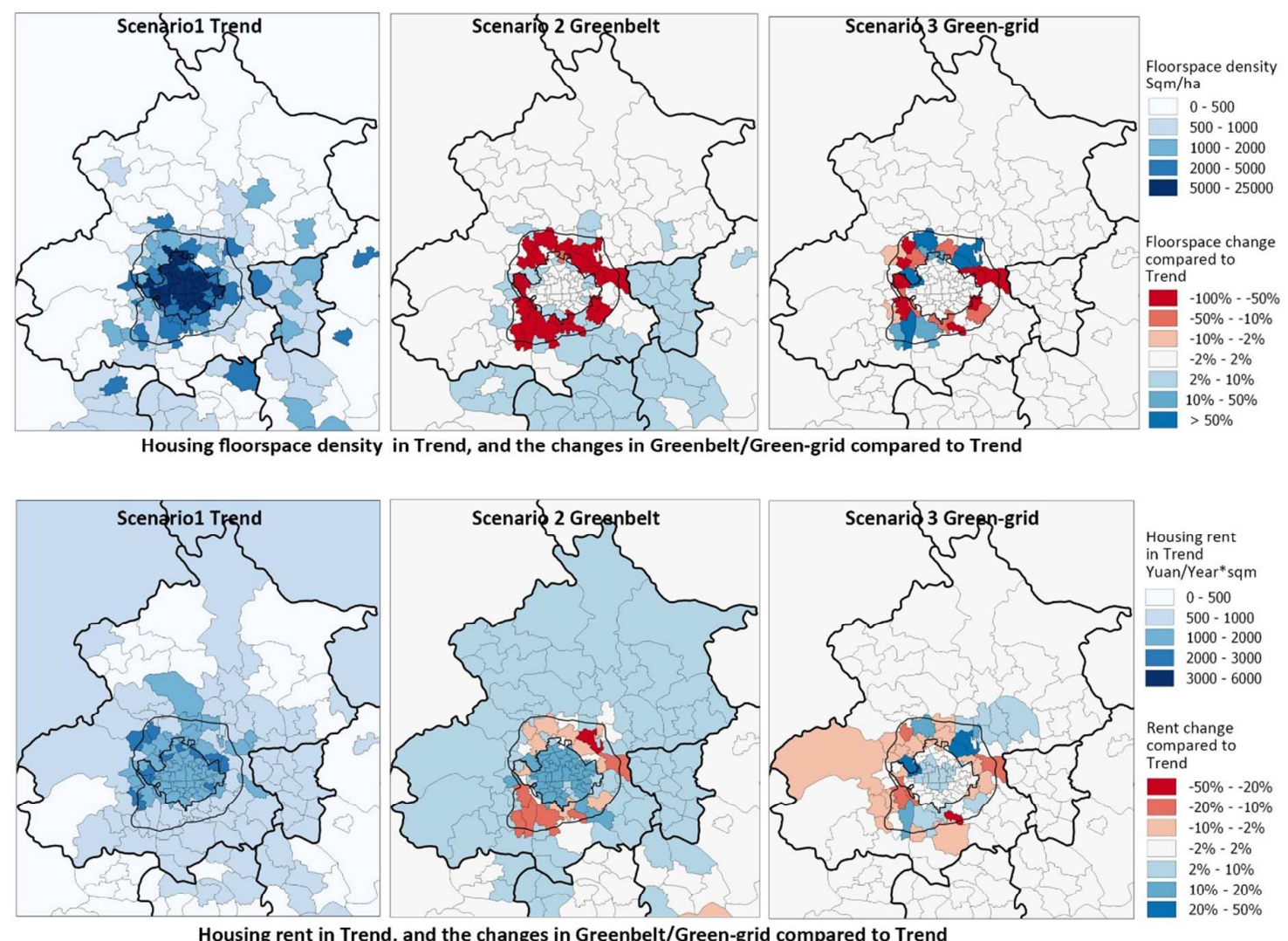

Housing rent in Trend Yuan/Year*sqm $0-500$

$500-1000$
$1000-2000$ $2000-3000$ 
Figure 6 Utility level in Trend, and the changes in Greenbelt/Green-grid compared to Trend

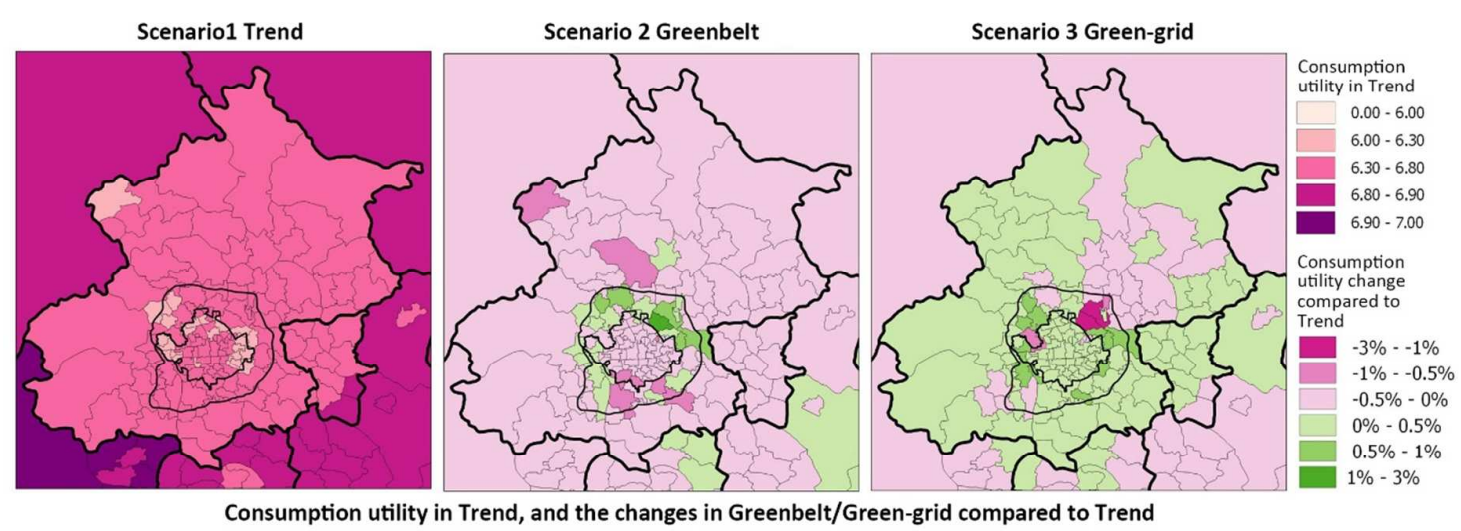




\section{Supplementary material 1: key equations}

Key equations are summarised following the order of 4 sub-models:

\section{Spatial Equilibrium Model}

Following the tradition of Anas and Liu (2007) and Jin, Echenique and Hargreaves (2013), the producers and consumers' behaviour follows a parsimonious design. It does not currently include explicit agency of developers or government, although these can be added at a later date which will result in a more complex model to calibrate and use. Taxes are not modelled explicitly; instead, the model assumes that the city balances its consumption with its production, and any increase in the property sales/rental income is shared equally among all households.

The production function follows a hybrid Cobb-Douglas CES form. Producers can choose any zone to locate. The output $X_{r j}$ of a certain industrial type $r$ in a zone $j$ is:

$$
X_{r j}=E_{r j} A_{r j}\left(K_{r}\right)^{v_{r}}\left(\sum_{f} \kappa_{r f j} L_{r f j}^{\theta_{r}}\right)^{\frac{\delta_{r}}{\theta_{r}}}\left(\sum_{k} \mathcal{H}_{r k j} B_{r k j}^{\zeta_{r}}\right)^{\frac{\mu_{r}}{\zeta_{r}}} \prod_{s}\left(Y_{r s j}\right)^{\gamma_{r s}} \quad \text { [Equation 1] }
$$

In this hybrid Cobb-Douglas CES function, primary inputs are the capital $K_{r}$, labour force $L_{f j}$, business floorspace $B_{k j}$ and intermediate inputs $Y_{r s j}$. The subscripts $f, k$ and $s$ stand for the types of labour force, business floorspace and goods respectively. $E_{r j}$ is scale parameter. $A_{r j}$ is the economic mass parameter which represents the urban agglomeration effects. This function is rendered constant returns by $v_{r}+\delta_{r}+\mu_{r}+\sum_{s} \gamma_{r s}=1$. The elasticity of substitution between any two types of labour forces and building floorspace are $\frac{1}{1-\theta_{r}}$ and $\frac{1}{1-\zeta_{r}}$. $\kappa_{r f j}$ and $\mathcal{H}_{r k j}$ are input-specific constants for choosing between types of labour forces and business floorspace.

Consumers are also categorised into $f$ types by their socio-economic status. They can work in any zone, live in any zone and purchase goods in any zone, subject to the maximised individual utility. Each consumer decides where to be employed and where to live based on a combined utility. Following the random utility framework (McFadden 1974), an individual in the population has an employment-resident location utility function: 


$$
U_{f i j}=V_{f i j}-d_{f i j}+E_{f i j}+e_{f i j}
$$

[Equation 2]

Where $V_{f i j}$ is the consumption utility of living in zone $i$ while working in zone $j$, which is non-stochastic and reflects the representative taste of the population, $d_{f i j}$ is the travel disutility from $i$ to $j, E_{f i j}$ is the residual attractiveness term for a zone pair $i j$ which is calibrated empirically. It represents the zonal characteristics that are not counted in consumption utility, for example the amenity value of greenspaces. The $e_{f i j}$ is stochastic and reflects the idiosyncrasies of the population. The non-stochastic consumption utility $V_{f i j}$ consists of three parts: the quantity of retail goods and service a consumer buys, the quantity of floorspace he/she rents, and the time he/she contributes to work or leisure. An individual consumption utility of a type $f$ consumer living in zone $i$, working in zone $j$ and shopping in any zone $z$ is written as:

$$
\begin{aligned}
V_{f i j}=\alpha_{f} & \ln \left(\sum_{r}\left(\sum_{z} Z_{r z \mid f i j}\right)^{\eta_{f}}\right)^{\frac{1}{\eta_{f}}}+\beta_{f} \ln \left(\sum_{k} l_{k f i}\left(b_{k f i}\right)^{\sigma_{f}}\right)^{\frac{1}{\sigma_{f}}} \quad \text { [Equation } \\
& +\gamma_{f} \ln l_{f i j}
\end{aligned}
$$

$\alpha_{f}, \beta_{f}, \gamma_{f}$ are the shares of disposable income spent on the retail goods and service $Z_{r z \mid f i j}$, housing floorspace $b_{f i j}$, and annual leisure time $l_{f i j}$ and they follow the Cobb-Douglas constant returns by defining $\alpha_{f}+\beta_{f}+\gamma_{f}=1$. The subscripts $r$ and $k$ stand for the type of goods and the type of housing floorspace respectively. $l_{k f i}$ is the input-specific constant for choosing the housing type $k$ for type $f$ consumer in zone $i \cdot \frac{1}{1-\eta_{f}}$ and $\frac{1}{1-\sigma_{f}}$ are respectively the elasticities of substitution between any two retail goods and any two types of housing.

For a given employment-residence location $i j$, by assuming the stochastic term $e_{f i j}$ follows Gumbel distribution, the probability for living in zone $i$ and working in zone $j$ is represented in a logit form:

$$
P_{f i j}=\frac{S_{i} \exp \left(\lambda_{f}\left(V_{f i j}-d_{f i j}+E_{f i j}\right)\right)}{\sum_{i} S_{i} \exp \left(\lambda_{f}\left(V_{f i j}-d_{f i j}+E_{f i j}\right)\right)}
$$


$S_{i}$ is a size parameter that corrects for the bias introduced by the uneven sizes of zones in the model. $\lambda_{f}$ is the concentration parameter for employment-residence location choice.

\section{Non-Commuting Travel Demand Model}

Given the zonal numbers of employed residents and workers, the Non-Commuting Travel Demand model generates non-employed individual persons within each type of household into different categories $c$ following a social accounting matrix. Then it generates noncommuting travel demands in line with the categories. Such categories are based on the noncommuting travel demand segments in survey. The travel demand generation also follows a social accounting matrix form.

$$
T_{i}^{t}=\sum_{c} a^{t c} Y_{i}^{c}
$$

[Equation 5]

$T_{i}^{t}$ is the total number of non-commuting trade type $t$ generated at the origin zone $i . Y_{i}^{c}$ is the number of individuals of category $c$ in zone $i$, and $a^{t c}$ is the trade generation matrix. Trade types $t$ are classified by travel purpose and within each purpose, by socio-economic group $f$.

As the trades are generated from the origins, another discrete choice model is used to select the destinations of non-commuting trades.

$$
T_{i j}^{t}=T_{i}^{t} \frac{S_{j}^{t} e^{-\lambda^{t}\left(d_{i j}^{t}+w_{j}^{t}\right)}}{\sum_{j} S_{j}^{t} e^{-\lambda^{t}\left(d_{i j}^{t}+w_{j}^{t}\right)}}
$$

$T_{i j}^{t}$ is the trade flow of non-commuting activities $t$ from zone $i$ to zone $j . T_{i}^{t}$ is the total trip generated from zone $i . S_{j}^{t}$ is the size parameter of type $t$ activities in zone $j . d_{i j}^{t}$ is the travel disutility of type $t$ activities from zone $i$ to zone $j . w_{j}^{t}$ is a constant, which varies according to the types of activities and zones.

\section{Strategic Transport Model}

Given the predicted travel demands from the Spatial Equilibrium Model and NonCommuting Travel Demand Model, the Strategic Transport Model distributes trips among different travel modes on each link, given a certain network supply. Given the total trip flows 
$F_{i j}^{t}$ (converted from trade $T_{i j}^{t}$ through trip generation matrix) for a specific OD pair from $i$ to $j$, the model distributes trips into modes based on a logit model:

$$
\begin{gathered}
F_{i j m}^{t}=F_{i j}^{t} \frac{e^{-\lambda_{m}^{t} D_{i j m}^{t}}}{\sum_{m} e^{-\lambda_{m}^{t} D_{i j m}^{t}}} \\
D_{i j m}^{t}=\phi^{t} c_{i j m}^{t}+t_{i j m}^{t}+p_{j m}^{t}+\Omega_{m}^{t}
\end{gathered}
$$

Where $F_{i j m}^{t}$ is the trips of type $t$ from zone $i$ to zone $j$ on mode $m$. The modal disutility $D_{i j m}^{t}$ consists of four elements: out-of-pocket travel cost $c_{i j m}^{t}$ converted into time units through the marginal utility of money $\phi^{t}$, travel time $t_{i j m}^{t}$, destination disutility (such as off-network travel time and parking fee) $p_{j m}^{t}$, and modal specific constant $\Omega_{m}^{t}$ (Jin et al. 2002). $\lambda_{m}^{t}$ is the concentration parameter for inter-zonal mode choice. Travel disutility $d_{i j}$ (in [Equation 2] and [Equation 6]) is the log-sum disutility of $D_{i j m}$ over all possible modes.

The cross-sectional model requires the following standard assumptions, given travel disutility $D_{i j m}^{t}$, subject to the zonal floorspace stock constraints by type $B_{r k j}$ and $b_{k f i}:$ 1) All consumers maximise utility subject to the housing floorspace, money and time constraints. 2) All producers minimise cost subject to the input factors, which are the floorspace and labour provision. 3) A zero profit condition is set for producers in an open competitive market. The market is zero excess demands in floorspace market, labour market and product market. In labour market, total working hours demand equals total non-leisure hours minus travel time. In product market, total goods and services produced equals total goods and service consumed by consumers.

\section{Recursive Dynamic Model}

After a cross-sectional simulation has finished at the first time horizon, the solved prices and quantities will serve as the starting point for the prediction of the next time horizon. The floorspace stocks will respond to urban change over two time horizons, and this is modelled in the Recursive Dynamic Model. The total floorspace stock is user-defined, because this is likely to be the most appropriate in order to reflect policy targets. On a zonal level, Recursive Dynamic Model distributes the total floorspace stock, subject to the spatial pattern from the equilibrium status in the last decade and the background policy trend. The zonal floorspace for a certain type is described in the equation below: 


$$
B_{k i}^{T+1}=B_{k i}^{T}+n B_{k}^{T \rightarrow T+1} \frac{B_{k i}^{T}}{\sum_{i} B_{k i}^{T}}+(1-n) B_{k}^{T \rightarrow T+1} \frac{\exp \left(\lambda_{b} V_{k i}\right)}{\sum_{i} \exp \left(\lambda_{b} V_{k i}\right)}
$$

$B_{k i}^{T}$ is the zonal floorspace stock at zone $i$ for time $T . B_{k i}^{T+1}$ is the zonal floorspace stock at zone $i$ for the next time section $T+1 . B_{k}^{T \rightarrow T+1}$ is the total regional stock change of floorspace from time $T$ to $T+1$ defined exogenously. The added regional stock $B_{k}^{T \rightarrow T+1}$ is split into two parts: natural growth $n B_{k}^{T \rightarrow T+1} \frac{B_{k i}^{T}}{\sum_{i} B_{k i}^{T}}$ and added growth $(1-n) B_{k}^{T \rightarrow T+1} \frac{\exp \left(\lambda_{B} V_{k i}\right)}{\sum_{i} \exp \left(\lambda_{B} V_{k i}\right)} . n$ is a user-specified portion of natural growth. The zonal natural growth is proportional to the existing stock size. The zonal added growth distribution follows a logit model with a concentration parameter $\lambda_{b} . V_{k i}$ is a non-stochastic location-based utility.

$$
V_{k i}=\beta_{1} \ln \sum_{k} B_{k i}^{T}+\beta_{2} \frac{\bar{R}_{k i}^{T}}{\bar{R}_{D}^{T}}+\beta_{3} \mathcal{D}_{k i}^{T}+\beta_{4} M_{k i}^{T}+\beta_{5} \beth_{k i}+E_{D}
$$

[Equation 10]

Variables in the equation are respectively the existing zonal stock size $\sum_{k} B_{k i}^{T}$, average rent over provincial average rent $\frac{\bar{R}_{k i}^{T}}{\bar{R}_{D}^{T}}$, zonal floorspace density $\mathcal{D}_{k i}^{T}$, economic mass $M_{k i}^{T}$, policy dummy variable $\beth_{k i}$ and provincial residual term $E_{D}$.

Major transport constructions tend to be the most durable and irreversible urban changes. Therefore, the most appropriate way to update the transport supply, namely the network in the model, is to add or demolish infrastructure according to the long term official development plan. Zones at the urban fringe which might be affected by different greenspace configurations will have a variable $A_{l}$ to represent the proximity from the built-up areas to the transport network.

$$
A_{l}=a_{l} r
$$

Where $A_{l}$ is the access link length from zonal centroids to the road access nodes or stations for built-form $l . r$ is the radius of the zone. $a_{l}$ is the ratio of access link length to radius for built-form $l . a_{l}$ is calculated using a generic urban form model (Holroyd 1966). Details of defining and validating $A_{l}$ can be found in Ma \& Jin (Ma \& Jin 2016).

\section{Model Assessment}


The overall consumer surplus, $\Delta \mathrm{C}$, as a household well-being measure may be defined as the change in average household utility divided by the average marginal utility of money.

$$
\Delta C=\frac{\left(\bar{U}_{\text {Alternative }}-\bar{U}_{\text {Base }}\right)}{\frac{1}{2}\left(\frac{1}{\bar{\Omega}_{\text {Alternative }}}+\frac{1}{\bar{\Omega}_{\text {Base }}}\right)}
$$

[Equation

where $\bar{U}_{\text {Base }}$ and $\bar{U}_{\text {Alternative }}$ are the average household utilities; $\bar{\Omega}_{\text {Base }}$ and $\bar{\Omega}_{\text {Alternative }}$ are the average household incomes for the base and alternative scenarios, respectively. 


\section{Supplementary material 2: parameters and data inputs for calibration}

The following charts list the parameters used in the four sub-models respectively. Sources are given for each group of parameters.

Most of the parameters are from officially published statistical yearbooks, censuses, travel surveys and input-output tables.

Parameters starred with * or ** are calibrated by the authors and are labelled "own calibration" in the charts. Data input for calibration are reported under each individual chart.

In general, there are four groups of calibrated parameters: firstly, by adjusting the concentration parameter $\lambda_{f}$ in Equation 4, the differences between the observed and modelled commuting distances and times should be less than $1 \%$. Secondly, by adjusting $E_{f i j}$ in Equation 4, the differences between the observed and modelled zonal numbers of population and jobs should be less than $0.1 \%$. Thirdly, by adjusting the concentration parameter $\lambda_{m}^{t}$ by each trip purpose in Equation 7, the differences between the observed and the modelled trip range distributions should be less than 3\%. Fourthly, by adjusting modal specific constant $\Omega_{m}^{t}$ in Equation 8, the differences between the observed and the modelled mode shares should be less than $1 \%$.

There are a few parameters that we do not currently have data to calibrate. In such cases, we have taken values that are proven to be fairly stable in the existing literature on models of this type. Such parameters are mainly concerning the elasticities of substitution among floorspace varieties and labour varieties. These parameters are selected through elasticity tests and based on previous studies (Anas \& Rhee 2006; Wan \& Jin 2017). With more data published in the future, the parameters could be estimated and modified for Greater Beijing. 


\section{Key parameters for the Spatial Equilibrium Model}

\begin{tabular}{|c|c|c|}
\hline Parameters & 2010 value & Sources \\
\hline$\delta_{r}$ labour cost share & 0.88 & Beijing IO table (2010) \\
\hline$\mu_{r}$ business floorspace cost share & 0.12 & Beijing IO table (2010) \\
\hline $\begin{array}{l}\zeta_{r} \text { elasticity of substitution for } \\
\text { business floorspace varieties }\end{array}$ & 0.90 & Anas and Rhee (2006) \\
\hline $\begin{array}{l}\theta_{r} \text { elasticity of substitution for } \\
\text { labour varieties }\end{array}$ & 0.75 & $\begin{array}{l}\text { Beijing-Tianjin-Hebei } \\
\text { Model, Wan (2016) }\end{array}$ \\
\hline $\begin{array}{l}\sigma_{f} \text { elasticity of substitution for } \\
\text { housing varieties }\end{array}$ & $\begin{array}{l}\text { high: } 0.90 \\
\text { mid: } 0.90 \\
\text { low: } 0.90\end{array}$ & Anas and Rhee (2006) \\
\hline $\begin{array}{l}E_{j} \\
\text { productivity multiplier }\end{array}$ & 1.00 & Anas and Rhee (2006) \\
\hline $\begin{array}{l}c_{f} \\
\text { Cost for delivering a unit of local } \\
\text { services as percentage of } \\
\text { commuting trip cost }\end{array}$ & 0.10 & Anas and Rhee (2006) \\
\hline $\begin{array}{l}\alpha_{f} \\
\text { utility coefficient for goods \& } \\
\text { services }\end{array}$ & $\begin{array}{c}\text { high: } 0.23 \\
\text { mid: } 0.27 \\
\text { low: } 0.30 \\
\text { non-emp.: } \\
0.50\end{array}$ & $\begin{array}{l}\text { Beijing statistical year book } \\
2011\end{array}$ \\
\hline $\begin{array}{l}\beta_{f} \\
\text { utility coefficient for housing }\end{array}$ & $\begin{array}{l}\text { high: } 0.17 \\
\text { mid: } 0.26 \\
\text { low: } 0.35\end{array}$ & $\begin{array}{l}\text { Beijing statistical year book } \\
2011\end{array}$ \\
\hline $\begin{array}{l}\gamma_{f} \\
\text { utility coefficient for leisure time }\end{array}$ & $\begin{array}{l}\text { high: } 0.60 \\
\text { mid: } 0.47 \\
\text { low: } 0.35\end{array}$ & $\begin{array}{l}\text { Beijing statistical year book } \\
2011\end{array}$ \\
\hline $\begin{array}{l}\lambda_{f} \\
\text { concentration parameter for } \\
\text { residence location choices }\end{array}$ & $\begin{array}{l}\text { high: } 3.25 \\
\text { mid: } 4.40 \\
\text { low: } 4.40\end{array}$ & $\begin{array}{l}\text { Own calibration using } \\
\text { observed commuting } \\
\text { statistics* }\end{array}$ \\
\hline
\end{tabular}


Key parameters for the Non-commuting Travel Demand Model

\begin{tabular}{cccccc}
\hline \hline $\begin{array}{c}\text { Households } \\
\text { type }\end{array}$ & $\begin{array}{c}\text { Children aged } \\
\mathbf{0 - 5}\end{array}$ & $\begin{array}{c}\text { Children aged 6- } \\
\mathbf{1 7}\end{array}$ & Retired & $\begin{array}{c}\text { Unemploye } \\
\text { d }\end{array}$ & Total \\
\hline High & 0.067 & 0.132 & 0.333 & 0.129 & 0.66 \\
Middle & 0.068 & 0.134 & 0.338 & 0.132 & 0.67 \\
Low & 0.106 & 0.210 & 0.530 & 0.206 & 1.05 \\
Non-employed & 0.019 & 0.382 & 1.580 & 0.352 & 2.33
\end{tabular}

Source: Beijing Statistical Yearbooks 2011 and 2016 population data (Beijing Bureau of Statistics 2016), available at: http://www.bjstats.gov.cn/zt/rkjd/, National Census 2011 (National Bureau of Statistics of China 2016), available at: http://data.stats.gov.cn/english/easyquery.htm?cn=E0103 


\begin{tabular}{cccc}
\hline \hline Individual type & School trip & Business trip & $\begin{array}{c}\text { Other } \\
\text { trip }\end{array}$ \\
\hline Employed worker & 0 & 4.35 & $0 *$ \\
Children aged 0-5 & 0 & 0 & 0 \\
Children aged 6-17 & 49.1 & 0.2 & 7.9 \\
Retired & 0 & 0.4 & 58.4 \\
unemployed & 0 & 0.6 & 53.1 \\
\hline College student & 49.1 & 0.2 & 7.9 \\
\hline Floating population & 0.1 & 6.1 & 25.3 \\
\hline
\end{tabular}

Source: The 4th Beijing Transport Survey Report (Beijing Transportation Research Centre 2012).

*We do not have data showing the number of other trips generated by employed workers. We assume the number of such trips in morning peak is few. 
Key parameters for the Strategic Transport Model

\begin{tabular}{|c|c|c|c|c|c|c|}
\hline \multirow[b]{2}{*}{$\begin{array}{c}\text { Flo } \\
\mathbf{w}\end{array}$} & \multicolumn{2}{|c|}{$\begin{array}{c}\text { Flow } \\
\text { description }\end{array}$} & \multirow{2}{*}{$\begin{array}{c}\text { Inter- } \\
\text { zonal } \\
\text { mode } \\
\text { choice } \\
\text { concentr } \\
\text { ation } \\
\text { paramet } \\
\text { ers } \\
\lambda_{m}^{t}\end{array}$} & \multirow{2}{*}{$\begin{array}{c}\text { Intra- } \\
\text { zonal } \\
\text { mode } \\
\text { choice } \\
\text { concentr } \\
\text { ation } \\
\text { paramet } \\
\text { ers } \\
\lambda_{m \mid B}^{t}\end{array}$} & \multirow[b]{2}{*}{$\begin{array}{c}\text { Modal specific } \\
\text { constants } \\
\Omega_{m}^{t}\end{array}$} & \multirow[b]{2}{*}{$\begin{array}{c}\text { Marginal utility } \\
\text { of money } \\
\text { (minute/cent) } \\
\phi^{t}\end{array}$} \\
\hline & $\begin{array}{c}\text { Trip } \\
\text { purpos } \\
\text { e }\end{array}$ & SEG & & & & \\
\hline 1 & $\begin{array}{l}\text { Commu } \\
\text { ting }\end{array}$ & $\begin{array}{l}\text { high } \\
\text { mid }\end{array}$ & 0.06 & 0.10 & & 0.046877 \\
\hline $\begin{array}{l}2 \\
3\end{array}$ & & $\begin{array}{l}\text { dle } \\
\text { low }\end{array}$ & $\begin{array}{l}0.07 \\
0.08\end{array}$ & $\begin{array}{l}0.11 \\
0.12\end{array}$ & & $\begin{array}{l}0.095804 \\
0.174834\end{array}$ \\
\hline 4 & $\begin{array}{c}\text { Educati } \\
\text { on }\end{array}$ & $\begin{array}{l}\text { high } \\
\text { mid }\end{array}$ & 0.06 & 0.10 & & 0.046877 \\
\hline $\begin{array}{l}5 \\
6\end{array}$ & & $\begin{array}{l}\text { dle } \\
\text { low }\end{array}$ & $\begin{array}{l}0.07 \\
0.08\end{array}$ & $\begin{array}{l}0.11 \\
0.12\end{array}$ & $\begin{array}{c}\text { varies among } \\
\text { SEG groups/trip }\end{array}$ & $\begin{array}{l}0.095804 \\
0.174834\end{array}$ \\
\hline 7 & $\begin{array}{c}\text { Busines } \\
\mathrm{s}\end{array}$ & $\begin{array}{l}\text { high } \\
\text { mid }\end{array}$ & 0.04 & 0.08 & purposes & 0.023439 \\
\hline $\begin{array}{l}8 \\
9\end{array}$ & & $\begin{array}{l}\text { dle } \\
\text { low }\end{array}$ & $\begin{array}{l}0.05 \\
0.06\end{array}$ & $\begin{array}{l}0.09 \\
0.10\end{array}$ & & $\begin{array}{l}0.047902 \\
0.087417\end{array}$ \\
\hline 10 & Other & $\begin{array}{l}\text { high } \\
\text { mid }\end{array}$ & 0.06 & 0.10 & & 0.046877 \\
\hline 11 & & dle & 0.07 & 0.11 & & 0.095804 \\
\hline 12 & & low & 0.08 & 0.12 & & 0.174834 \\
\hline $\begin{array}{l}\text { Sou } \\
\text { rce }\end{array}$ & & & $\begin{array}{r}\text { LASE } \\
\text { Depart } \\
\text { Transport }\end{array}$ & $\begin{array}{l}\text { 3.0, } \\
\text { \& MEnt of } \\
\text { \& } P\end{array}$ & $\begin{array}{c}\text { Own calibration } \\
\text { based on } \\
\text { observed mode }\end{array}$ & $\begin{array}{c}\text { Own calibration } \\
\text { from income } \\
\text { level** }\end{array}$ \\
\hline
\end{tabular}


shares and trip

range

distribution*

* Observed mode shares by trip purposes and observed trip range distribution can be found in The 4th Beijing Transport Survey Report (Beijing Transportation Research Centre 2012) and The 5th Beijing Transport Survey Report (Beijing Transportation Research Centre 2016).

** Income level is derived from Beijing Statistical Yearbooks 2011 and 2016 (Beijing Bureau of Statistics 2016) Available at: http://www.bjstats.gov.cn/zt/rkjd/

Key parameters for the Recursive Dynamic Model

\begin{tabular}{|c|c|c|}
\hline Parameters & Values & Sources \\
\hline \multicolumn{3}{|c|}{ Housing floorspace update } \\
\hline$\beta_{1}$ & 0.513 & Beijing-Tianjin-Hebei \\
\hline coefficient for $\ln \sum_{k} B_{k i}^{T}$ & & Model, Wan (2016) \\
\hline$\beta_{2}$ & 0.005 & \\
\hline \multicolumn{3}{|l|}{ coefficient for $\frac{\overline{\bar{R}_{k l}^{T}}}{\bar{R}_{D_{l}}^{T}}$} \\
\hline$\beta_{3}$ & -0.014 & \\
\hline \multicolumn{3}{|l|}{ coefficient for $\mathcal{D}_{k i}^{T}$} \\
\hline$\beta_{4}$ & 0.124 & \\
\hline \multicolumn{3}{|l|}{ coefficient for $M_{k i}^{T}$} \\
\hline$\beta_{5}$ & 0.965 & \\
\hline \multicolumn{3}{|l|}{ Coefficient for $\beth_{k i}$} \\
\hline$E_{D}$ & Beijing: -0.613 & \\
\hline residual attractiveness term & Tianjin: 0.564 & \\
\hline for BFS growth & Hebei: 0.050 & \\
\hline
\end{tabular}

Business floorspace update

\begin{tabular}{lcc}
\hline$\beta_{1}$ & 0.872 & $\begin{array}{c}\text { Beijing-Tianjin-Hebei Model, } \\
\text { Wan (2016) } \\
\text { coefficient for } \ln \sum_{k} B_{k i}^{T}\end{array}$ \\
\cline { 1 - 2 } & 0.009 &
\end{tabular}


References and data sources:

Anas, A. \& Rhee, H.-J., 2006. Curbing excess sprawl with congestion tolls and urban boundaries. Regional Science and Urban Economics, 36(4), pp.510-541.

Beijing Bureau of Statistics, 2016. Beijing Bureau of Statistics. population data. Available at: http://www.bjstats.gov.cn/zt/rkjd/ [Accessed September 12, 2016].

Beijing Bureau of Statistics \& NBS Survey office in Beijing, 2009. Beijing 60 Years 19492009, China Statistic Press.

Beijing Transportation Research Centre, 2012. The 4th Beijing transport survey report,

Beijing Transportation Research Centre, 2016. The 5th Beijing transport survey report,

National Bureau of Statistics of China, 2016. National Data Webpage. Available at: http://data.stats.gov.cn/english/easyquery.htm?cn=E0103 [Accessed November 4, 2016].

Wan, L., 2016. A Recursive Spatial Equilibrium Model for the Beijing-Tianjin_Hebei City Region.

Wan, L. \& Jin, Y., 2017. Assessment of model validation outcomes of a new recursive spatial equilibrium model for the Greater Beijing. Environment and Planning B: Urban Analytics and City Science, p.239980831773257. 
56

57

58

59 


\section{Supplementary material 3: a comparison between a static model and a recursive model} for modelling greenspaces

In order to highlight the difference between the traditional static model and our recursive model, we did a parallel test that is to run the model statically. In the static run, zonal floorspace supplies in 2030 are calculated based on the information from the base year 2010. In the recursive run in the last section, zonal floorspace supplies in 2030 are calculated based on the information in 2020, and the 2020 supplies are calculated based on the information in 2010. In other words, the static model jumps from the base year to future years, while the recursive model takes cues from the recent development trend and updates constraints periodically.

Table 1 compares the predicted scales of productivity, floorspace, population, and employment between the static run and the recursive run under the Trend scenario. In the recursive run, the total production is $5 \%$ higher in Beijing. This is because the recursive model considers the cumulative urban agglomeration effect over two decades, instead of only the economic size in 2010. The higher productivity in the recursive run leads to higher business floorspace demand and labour demand.

Table 1 Comparison of constrains of static modelling and recursive modelling procedure for Beijing

\begin{tabular}{|c|c|c|c|}
\hline & $\begin{array}{l}\text { Static modelling } \\
\text { procedure }\end{array}$ & $\begin{array}{l}\text { Recursive modelling } \\
\text { procedure }\end{array}$ & $\begin{array}{c}\text { Difference } \\
\text { Recursive } \\
\text { vs Static }\end{array}$ \\
\hline $\begin{array}{l}\text { Total production in quantity of } \\
\text { composite goods (millions) }\end{array}$ & 5,422 & 5,687 & $5 \%$ \\
\hline $\begin{array}{l}\text { Housing floorspace supply } \\
\qquad\left(\text { million } \mathbf{m}^{2}\right)\end{array}$ & 1,186 & 1,169 & $-1 \%$ \\
\hline $\begin{array}{c}\text { Business floorspace supply } \\
\left.\text { (million } \mathbf{m}^{2}\right)\end{array}$ & 437 & 461 & $5 \%$ \\
\hline $\begin{array}{c}\text { Employed residents (Thousand } \\
\text { people) }\end{array}$ & 18,123 & 18,887 & $4 \%$ \\
\hline $\begin{array}{c}\text { Employed workers (Thousand } \\
\text { people) }\end{array}$ & 18,158 & 18,980 & $5 \%$ \\
\hline
\end{tabular}


For predicting impacts of greenspaces in a city under fast transformation, the recursive modelling procedure appears to have advantages. This is because greenspaces take a long time to shape and the development trend will constantly interact with the implementation of greenspaces over time. Defining modelling constraints and assumptions for future years only based on the information from the base year may not be suitable any more. This requires modellers to adjust the model constraints constantly as a city grows. The recursive model addresses this issue by periodically updating development constraints using the information from the previous decade. 